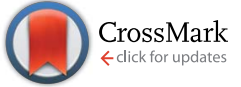

Cite this: RSC Adv., 2017, 7, 8347
Received 24th November 2016 Accepted 10th January 2017

DOI: $10.1039 / c 6 r a 27255 j$

www.rsc.org/advances

\section{Thermal decomposition of isolated and crystal 4,10-dinitro-2,6,8,12-tetraoxa-4,10- diazaisowurtzitane according to ab initio molecular dynamics simulations $\uparrow$}

\begin{abstract}
Dong Xiang and Weihua Zhu*
We performed ab initio molecular dynamics simulations to study the initiation chemical reaction and subsequent decomposition mechanism of a 4,10-dinitro-2,6,8,12-tetraoxa-4,10-diazaisowurtzitane (TEX) crystal at $2160 \mathrm{~K}$. It was found that there are three different initial reactions involved in the decomposition of an isolated TEX molecule. The activation energy barriers for the initial decomposition reactions indicate that among the three initial reaction paths, cleavage of the nitrogen-nitro bond is the easiest path to be triggered. The decomposition of the TEX crystal is triggered by the unimolecular $\mathrm{C}-\mathrm{H}$ bond breaking to form a hydrogen radical. The generated $\mathrm{H}$ radicals can prompt other unreacted TEX molecules to decompose. Moreover, there are many multimolecular reactions during the decomposition of the TEX crystal. Overall, after the decomposition of TEX was triggered, some long chains and complicated carbon-rich heterocyclic rings were formed, and then they split to form small fragments. This study may provide useful information to understand the decomposition mechanism of cage explosives and develop new high-energy explosives.
\end{abstract}

\section{Introduction}

In recent years, 4,10-dinitro-2,6,8,12-tetraoxa-4,10diazaisowurtzitane (TEX) has attracted attention as a novel energy material with a cage structure due to its high performance, high thermal stability, and insensitivity towards external stimuli. ${ }^{1}$ TEX (Fig. 1a) possesses the same isowurtzitane cage structure as CL-20 (2,4,6,8,10,12-hexanitro- $2,4,6,8,10,12$ hexaazaisowurtzitane or HNIW), which is one of the most powerful high explosives that have been synthesized to date, and it also has a relatively high ambient temperature density of $1.99 \mathrm{~g}$ $\mathrm{cm}^{-3} .^{2}$ The absence of sterically demanding nitramine groups in the TEX structure greatly reduces its sensitivity greatly and makes it an interesting insensitive energetic material $\left(h_{50}>177 \mathrm{~cm}\right) \cdot{ }^{3}$ Its heat of formation, detonation velocity, and detonation pressure were calculated to be $-541 \mathrm{~kJ} \mathrm{~mol}^{-1}, 8665 \mathrm{~m} \mathrm{~s}^{-1}$, and $41.03 \mathrm{GPa}$, respectively. ${ }^{4}$ To understand the complex behavior of explosives, to control risk during their usage and storage, and to develop new high-energy explosives, it is necessary to study the structure and

Institute for Computation in Molecular and Materials Science, Department of Chemistry, Nanjing University of Science and Technology, Nanjing 210094, China. E-mail: zhuwh@njust.edu.cn

$\dagger$ Electronic supplementary information (ESI) available: Calculated relative energies and entropies of the TEX molecule, intermediates, and transition states, calculated frequencies and IRC calculation results of the transition states. See DOI: 10.1039/c6ra27255j. properties of TEX as it has a special structure and exhibits excellent performance under extreme conditions.

It is known that information on the thermal decomposition mechanisms of explosives is useful for understanding their behavior at high temperatures. However, it is extremely difficult to obtain a clear molecular-level picture of the thermal decomposition of explosives through experimental measurements due to their complex behavior and the risks associated with them. An alternative approach is atomistic simulation, which is an effective way to model the physical and chemical properties of complex solids at the atomic level under high temperature conditions. The advances in $a b$ initio molecular dynamics (AIMD) methodology, make it possible to study the complex chemical phenomena of explosives at high temperatures. Recently, AIMD has been successfully applied to study the thermal decomposition of explosives. ${ }^{7-11}$ For example, Isayev et $a l^{8}$ performed a series of $a b$ initio molecular dynamics simulations to improve the atomistic understanding of the thermal decomposition of gaseous and solid CL-20 at high temperatures. Wu et al. ${ }^{9}$ performed $a b$ initio molecular dynamics simulations to investigate the thermal decomposition of 3,6-di(azido)-1,2,4,5-tetrazine (DiAT) at $3000 \mathrm{~K}$. Ye et al. ${ }^{10}$ unraveled the initial decomposition reactions of bicyclicHMX via ab initio molecular dynamics simulations. Although these studies provide important information for understanding the initial decomposition reactions of the explosives, full picture of their decomposition mechanisms is as complex as far from completion. 


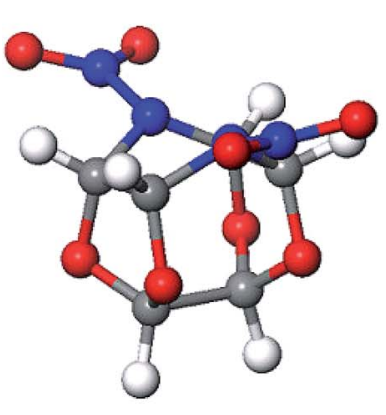

(a)

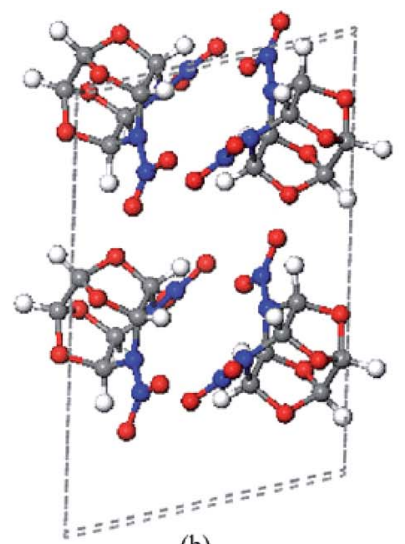

(b)

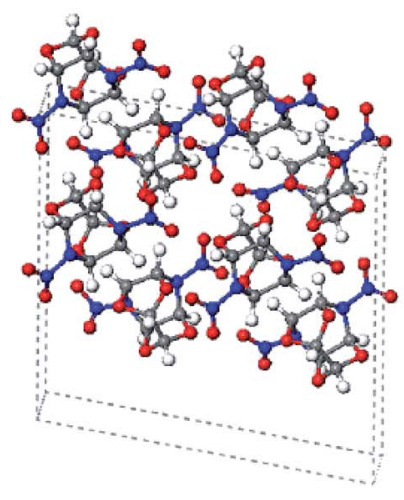

(c)

Fig. 1 Molecular structure of TEX (a) and $2 \times 1 \times 1$ (b) and $3 \times 1 \times 1$ supercells (c) of TEX crystal. Gray, blue, red, and white spheres stand for carbon, nitrogen, oxygen, and hydrogen atoms, respectively.

In this study, we performed AIMD simulations to study the chemical events involved in the initial decomposition reactions of unimolecular and crystalline TEX at high temperatures.

\section{Computational methods}

AIMD simulations were performed within the framework of density functional theory (DFT) $)^{12,13}$ based on the CASTEP code $^{14}$ using Troullier-Martins norm-conserving pseudopotentials ${ }^{15}$ and a plane-wave expansion of the wave functions. Moreover, the Perdew-Burke-Ernzerhof ${ }^{16}$ (PBE) exchange-correlation function was employed. We applied a plane wave cut-off of $500 \mathrm{eV}$ for the MD simulations and $900 \mathrm{eV}$ for geometry optimizations and energy calculations. In addition, the ionic temperature was controlled using a Nosé thermostat in the NVT ensemble. ${ }^{17}$ The initial positions of the simulation supercell were obtained from the experimentally determined X-ray crystal structure. ${ }^{18}$ The convergence criteria were as follows: an energy difference of $1 \times 10^{-5} \mathrm{eV}$ for solving the electronic wave functions and a force of $1 \times 10^{-3} \mathrm{eV}$ for structural optimizations. We used bond length and lifetime criteria to identify the changes in the geometry during the simulations. It was observed that a new bond is formed between two atoms when the smallest distance between them is larger than 0.6 times the ideal bond length, whereas a bond is ruptured when the largest distance between them is greater than 1.15 times the ideal bond length. For atoms bonded to hydrogen, the lifetime criterion must be met for at least $20 \mathrm{fs}$, whereas atoms that are not bonded to hydrogen (e.g. $\mathrm{C}-\mathrm{C}, \mathrm{N}-\mathrm{N}, \mathrm{N}-\mathrm{O}$, etc.) must survive for $45 \mathrm{fs}$.

To study the unimolecular decomposition of an isolated TEX molecule, one optimized TEX molecule at $0 \mathrm{~K}$ was placed in the center of a $18.0 \AA$ cubic periodic cell. The $18.0 \AA$ cubic box is large enough to prevent interactions between the periodic images. ${ }^{8}$ The system was first equilibrated at $298.15 \mathrm{~K}$ for $15 \mathrm{ps}$ with a time step of $1.0 \mathrm{fs}$ using the NVT ensemble, and then heated to $2160 \mathrm{~K}$. After this, $a b$ initio MD simulations were carried out using a time step of $1.0 \mathrm{fs}$ at $2160 \mathrm{~K}$ for $15 \mathrm{ps}$. To provide appropriate statistical sampling and obtain more reliable results, we performed 10 independent simulations of the unimolecular decomposition process. The Mulliken bond orders of TEX were calculated in the gas phase at the B3LYP/6$311+\mathrm{G}(\mathrm{d}, \mathrm{p})$ level. We located the nearby transition states (TSs), which were confirmed to have exactly one negative eigenvalue of the Hessian, in the gas phase at UB3LYP/6-311+g(d,p) level. The geometries and energies of the reactants and products were calculated at the B3LYP/6-311+G(d,p) level. In our previous studies, this method has been demonstrated to be reliable for studying organic explosive molecules. ${ }^{9,19}$ Then, we followed the reaction path by intrinsic reaction coordinate (IRC) scans to connect the structures of the reactants and products.

The thermal decomposition of crystalline TEX was simulated using a $2 \times 1 \times 1$ unit cell ( 4 TEX molecules, 96 atoms, as shown in Fig. 1b). After the system was equilibrated at $298.15 \mathrm{~K}$ for $15 \mathrm{ps}$ with a time step of $1.0 \mathrm{fs}$, ab initio MD simulations were

Table 1 Experimental and calculated bond lengths $(\AA)$ and angles $\left(^{\circ}\right)$ for the TEX $\operatorname{crystal}^{a}$

\begin{tabular}{|c|c|c|c|c|c|}
\hline Bond lengths & Expt. $^{20}$ & Cal. & Bond angles & Expt. $^{20}$ & Cal. \\
\hline $\mathrm{N}_{4}-\mathrm{O}_{4}$ & 1.225 & $1.236(-0.89)$ & $\mathrm{O}_{4}-\mathrm{N}_{4}-\mathrm{N}_{3}$ & 117.073 & $116.436(0.54)$ \\
\hline $\mathrm{N}_{4}-\mathrm{N}_{3}$ & 1.396 & $1.432(-2.58)$ & $\mathrm{N}_{3}-\mathrm{C}_{3}-\mathrm{O}_{7}$ & 112.183 & $112.117(0.06)$ \\
\hline $\mathrm{C}_{3}-\mathrm{O}_{7}$ & 1.421 & $1.423(-0.14)$ & $\mathrm{O}_{4}-\mathrm{N}_{4}-\mathrm{N}_{3}-\mathrm{C}_{2}$ & -167.774 & $-168.930(-0.69)$ \\
\hline $\mathrm{C}_{5}-\mathrm{C}_{6}$ & 1.557 & $1.600(-2.76)$ & $\mathrm{C}_{1}-\mathrm{N}_{1}-\mathrm{C}_{4}-\mathrm{O}_{8}$ & -57.907 & $-58.518(-1.06)$ \\
\hline
\end{tabular}

${ }^{a}$ The values in parentheses correspond to the percentage differences relative to the experimental data. 
Table 2 Bond orders of five different types of bonds of the TEX molecule

\begin{tabular}{llllll}
\hline Bond & $\mathrm{N}_{1}-\mathrm{N}_{2}$ & $\mathrm{C}_{1}-\mathrm{O}_{5}$ & $\mathrm{C}_{1}-\mathrm{C}_{2}$ & $\mathrm{C}_{5}-\mathrm{C}_{6}$ & $\mathrm{C}_{1}-\mathrm{N}_{1}$ \\
Bond order & 0.177 & 0.227 & 0.288 & 0.211 & 0.288
\end{tabular}

carried out at $2160 \mathrm{~K}$ with a time step of 1.0 fs for $130 \mathrm{ps}$. Moreover, to verify the size dependence of the system, we performed one additional large-scale simulation with a larger $3 \times 1$ $\times 1$ supercell ( 8 TEX molecules, 144 atoms, as shown in Fig. 1c) at $2160 \mathrm{~K}$ for $15 \mathrm{ps}$ with a $1.0 \mathrm{fs}$ time step after the system was equilibrated at $298.150 \mathrm{~K}$ for $15 \mathrm{ps}$.

\section{Results and discussion}

TEX crystallizes in a monoclinic lattice with a $P 1$ space group and contains two molecules per unit cell (48 atoms). Our optimized lattice parameters are $a=82.12, b=74.94$, and $c=78.91$ $\AA$, which are in agreement with the experimental lattice parameters $(a=82.37, b=75.05$, and $c=79.46 \AA),{ }^{20}$ with an average error of $0.6 \%$. The density of TEX was calculated to be $1.91 \mathrm{~g} \mathrm{~cm}^{-3}, 4 \%$ smaller than the experimental density. In addition, the calculated bond lengths, bond angles, and dihedral angles of TEX compare well with the experimental values, as shown in Table 1. All the results validate the reliability of our

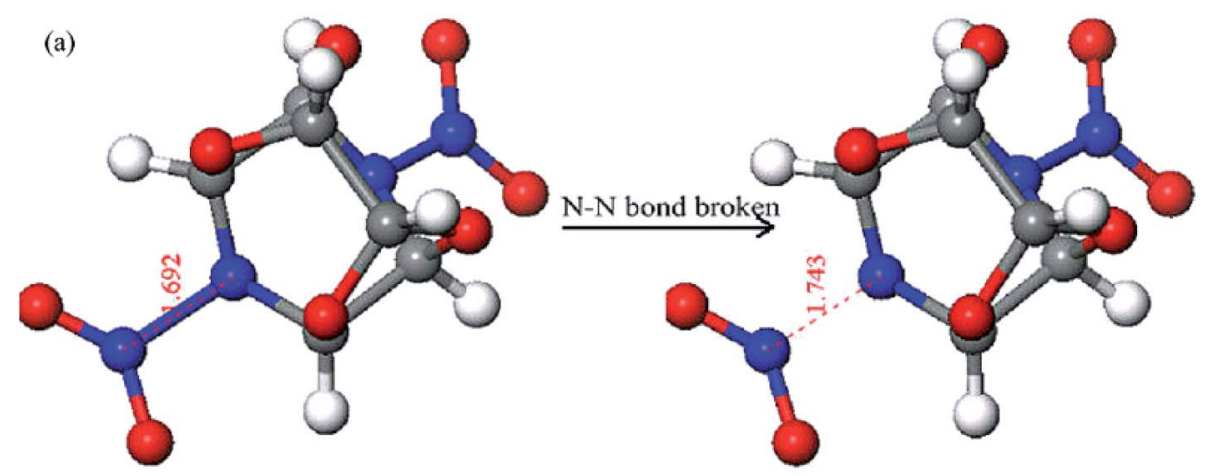

(b)

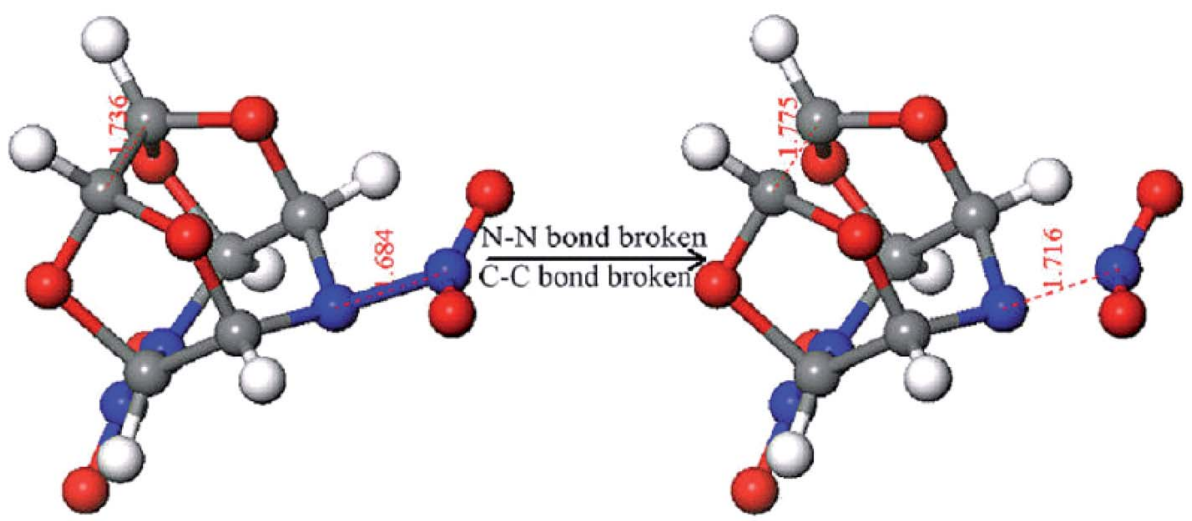

(c)

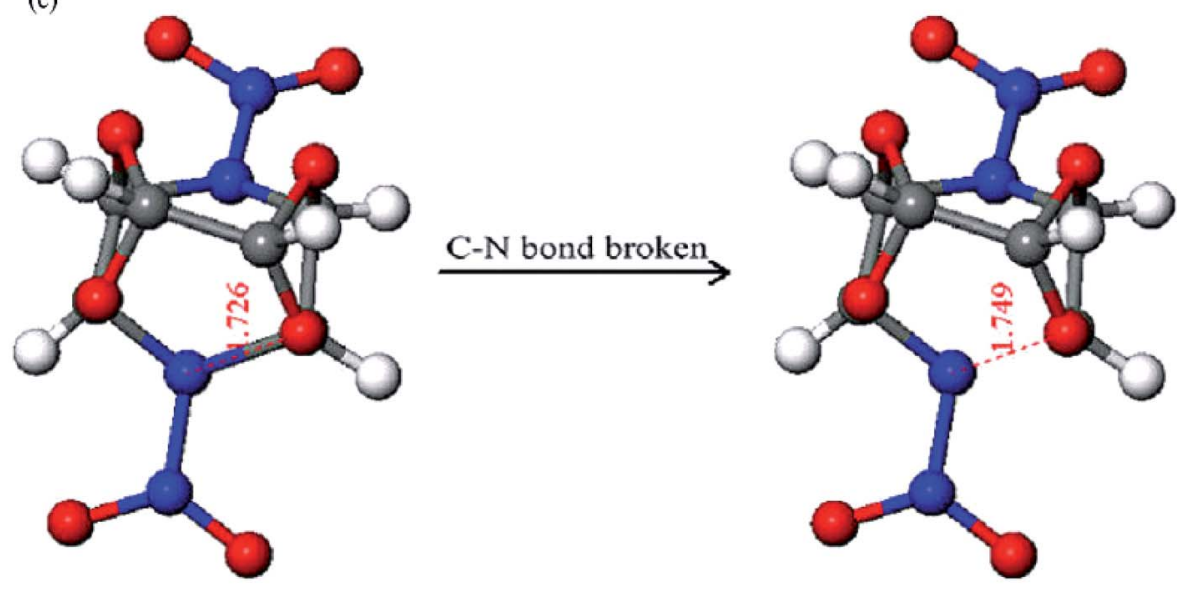

Fig. 2 Snapshots of three different initiation reactions in the thermal decomposition of the isolated TEX molecule. 
calculations and indicate that PBE-G06 is appropriate to study the TEX crystal.

\subsection{Decomposition mechanism of the isolated TEX molecule}

Table 2 lists the bond orders of five different types of bonds in a single TEX molecule at B3LYP/6-311+G(d,p) level. It was found that among these bonds, the $\mathrm{N}_{1}-\mathrm{N}_{2}$ bond has the smallest bond order. This indicates that it may be the weakest bond and its cleavage will trigger the decomposition of the TEX molecule.

From the ten independent simulations conducted on the isolated TEX molecule at $2160 \mathrm{~K}$, three different initial decomposition reactions were observed and the corresponding snapshots are shown in Fig. 2. These include (a) the $\mathrm{N}-\mathrm{NO}_{2}$ bond cleavage to release $\mathrm{NO}_{2}$, (b) the $\mathrm{N}-\mathrm{NO}_{2}$ bond cleavage and ring opening in the concerted step, and (c) the ring opening via the cleavage of a C-C bond. It can be seen in Fig. 2a that the $\mathrm{N}-\mathrm{NO}_{2}$ bond length changes from 1.692 to $1.743 \AA$. In addition, the N$\mathrm{NO}_{2}$ cleavage has a lifetime of approximately 0.6 ps. Fig. $2 \mathrm{~b}$ indicates that the $\mathrm{N}-\mathrm{NO}_{2}$ bond length changes from 1.684 to $1.716 \AA$ and the $\mathrm{C}-\mathrm{C}$ bond length changes from 1.736 to $1.775 \AA$.
Moreover, the $\mathrm{C}-\mathrm{N}$ bond length varies from 1.726 to $1.749 \AA$, as shown in Fig. 2c. The bond cleavages shown in Fig. $2 \mathrm{~b}$ and $\mathrm{c}$ have a slightly smaller lifetime at a given temperature than that shown in Fig. 2a. Compared with path (a), as shown in Fig. 2a, the appearance incidence of paths (b), as shown in Fig. 2b, and (c), as shown in Fig. 2c, is very low. Therefore, the $\mathrm{N}-\mathrm{NO}_{2}$ fission predominated in the early thermal decomposition stages of the TEX molecule. The homolysis of all $\mathrm{N}-\mathrm{NO}_{2}$ bonds took place within the time range of $0.085-0.152 \mathrm{ps}$, which is in agreement with the conclusion drawn from the bond order analysis. Isayev et $a l .{ }^{8}$ reported only one distinct initial reaction in the thermal decomposition of CL-20: the cleavage of the $\mathrm{N}-\mathrm{NO}_{2}$ bond before a cage-opening reaction. ${ }^{7}$ This is similar to the initial decomposition reaction for the TEX molecule studied herein. The paths (b) and (c) have not been reported in the thermal decomposition of other nitramine explosives (e.g., CL-20, RDX, HMX, etc. .). ${ }^{21,22}$ Moreover, subsequently generated intermediates during these three initial decomposition paths are different from those in the unimolecular decomposition of the isolated TEX molecule. This should be confirmed by further experimental studies.

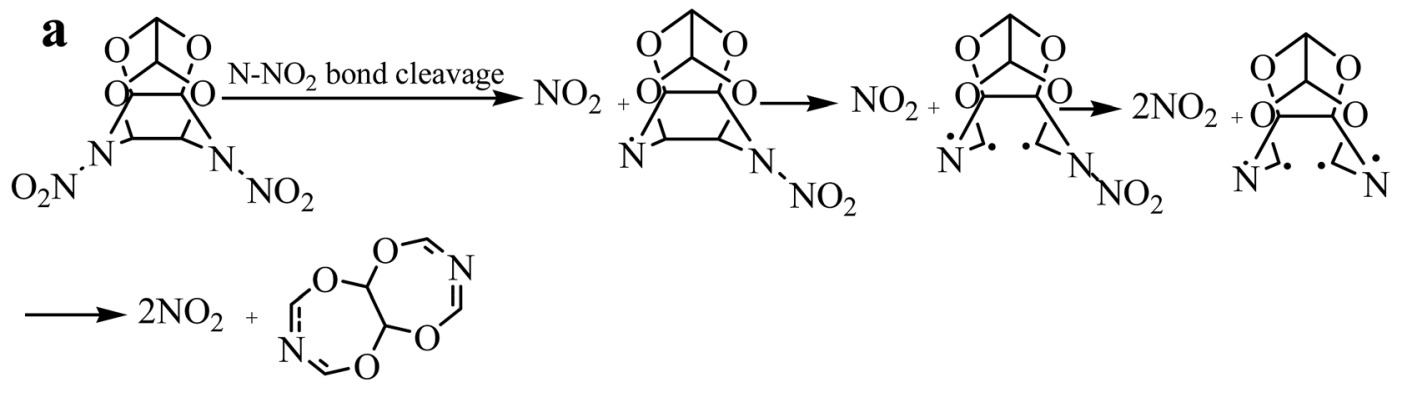<smiles>CC(C)[N+](=O)[O-]</smiles><smiles>CC(C)[N+](=O)[O-]</smiles>

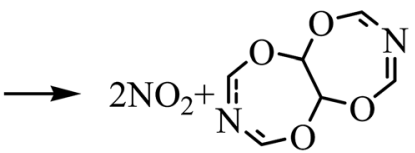

Fig. 3 Three decomposition paths for the isolated TEX molecule. 
More detailed decomposition processes that occur after the three initiation reactions are shown in Fig. 3. After the TEX explosion was triggered by the three different initial decomposition reactions, the subsequent decomposition intermediates were examined. It was found that the cage-opening mechanisms of the TEX molecules are different: the cage breaking by the $\mathrm{C}_{1}-$ $\mathrm{C}_{2}$ cleavage predominates, whereas that by the $\mathrm{C}_{3}-\mathrm{C}_{4}$ fission is occasional. After cage opening, subsequent decomposition processes are accompanied by the cleavage of the $\mathrm{C}-\mathrm{O}$ and $\mathrm{C}-\mathrm{N}$ bonds to form various types of radicals and release $\mathrm{NO}_{2}$. Most of the radicals are very unstable. For example, one TEX molecule rapidly decomposed into two nitrogen molecules and one heterocyclic radical. The heterocyclic radical further decomposed to form several different small fragments. Some small intermediates decomposed in a stepwise manner to produce $\mathrm{HCN}$ molecules. Others were oxidized by $\mathrm{NO}_{2}$ that lead to further decomposition, forming one to two HCN molecules (depending on bond length) and yielding simpler methyleneformamide carbenes. Although our AIMD simulations were performed on an isolated TEX, the results provided an important qualitative picture for understanding its initial thermal decomposition.
To further understand the mechanisms of these initial decomposition paths for the TEX molecule, we extracted the activated intermediates from the condensed phase simulations and searched the TS for each pathway in the gas-phase unimolecular reactions. The potential energy profiles for the three initial decomposition paths calculated in the gas phase are shown in Fig. 4. Calculated relative energies and entropies of TEX, intermediates, and transition states are listed in the Table S1 of the ESI. $\dagger$ Calculated frequencies and IRC calculation results of the transition states are listed in Table S2 and Fig. S1 of the ESI, $\dagger$ respectively. The reaction path (a) is the cleavage of the $\mathrm{N}-\mathrm{NO}_{2}$ bond via TS1 to form an intermediate Int1 with an energy barrier of $51.5 \mathrm{kcal} \mathrm{mol}^{-1}$. Then, the $\mathrm{C}_{1}-\mathrm{C}_{2}$ bond of the intermediate Int1 breaks via TS2 to form an intermediate Int2, which has an energy barrier of $5 \mathrm{kcal} \mathrm{mol}^{-1}$. Thus, the total energy barrier is $56.5 \mathrm{kcal} \mathrm{mol}^{-1}$. Moreover, there is another path to form Int 2 that is the simultaneous cleavage of the nitrogen-nitro bond and ring opening via TS5. This decomposition reaction has a high energy barrier $\left(321.6 \mathrm{kcal} \mathrm{mol}^{-1}\right)$ to produce Int2 than the former path. Subsequently, the $\mathrm{N}-\mathrm{NO}_{2}$ bond in Int2 breaks via TS3 ( $5 \mathrm{kcal} \mathrm{mol}^{-1}$ ) to give an intermediate Int 3 and release one molecule of $\mathrm{NO}_{2}$. The cage structure

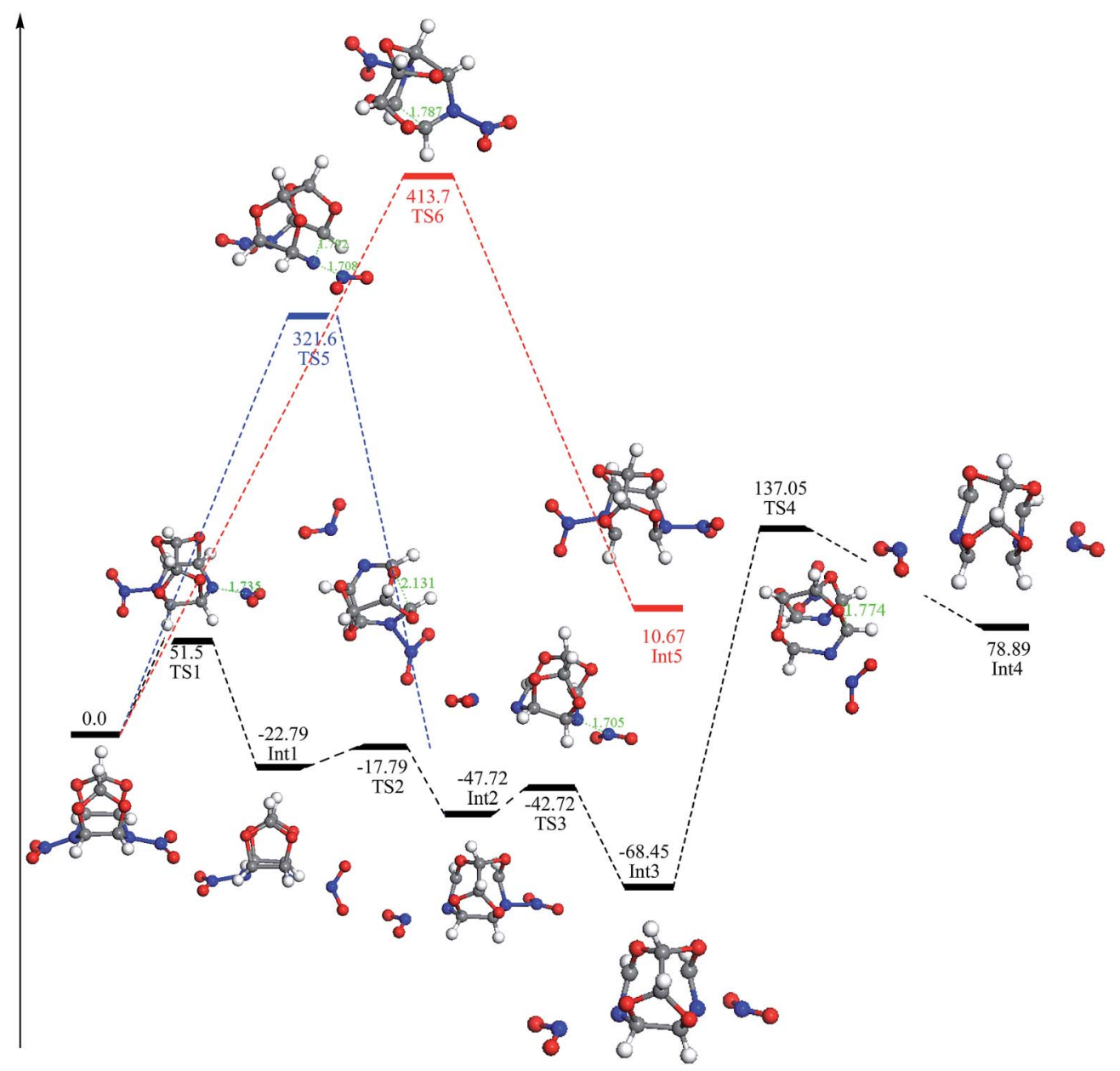

Fig. 4 Energy paths of the unimolecular decomposition mechanism of the isolated TEX molecule obtained from the gas-phase calculations based on the reactive intermediates extracted from the AIMD trajectory. The black, blue, and red lines correspond to paths (a), (b), and (c),

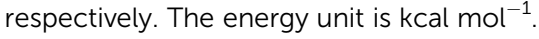




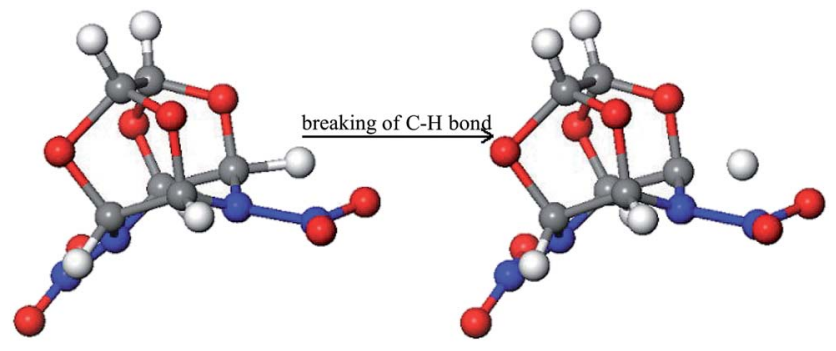

Fig. 5 Initial decomposition step of the crystal TEX molecule.

of Int3 is opened by the cleavage of $\mathrm{N}-\mathrm{NO}_{2}$ bond via TS4 (205.5 kcal $\mathrm{mol}^{-1}$ ) to give an intermediate Int4, which has a fused cyclic structure. The third decomposition path is the ring opening at the $\mathrm{C}_{1}-\mathrm{C}_{2}$ bond via TS6 to form an intermediate Int5, which has an energy barrier of $413.5 \mathrm{kcal} \mathrm{mol}^{-1}$. The energy barrier values increase in the following order: nitrogen-nitro cleavage $<$ the nitrogen-nitro cleavage and ring opening in the concerted step $<$ ring opening. This indicates that at high temperatures, among these three initial reactions, the nitrogennitro cleavage is the easiest path to trigger the decomposition of the TEX molecule.

\subsection{Decomposition mechanism of crystalline TEX}

Fig. 5 presents the initial decomposition mechanism of the TEX crystal. It was found that the initial decomposition is triggered by the unimolecular cleavage of the $\mathrm{C}-\mathrm{H}$ bond to form a hydrogen radical. This is different from the initial decomposition paths of the isolated TEX molecule: (a) $\mathrm{N}-\mathrm{NO}_{2}$ bond cleaves to release $\mathrm{NO}_{2}$; (b) the $\mathrm{N}-\mathrm{NO}_{2}$ bond cleavage and ring opening in the concerted step; and (c) ring opening through the cleavage of the $\mathrm{C}-\mathrm{C}$ bond. The local molecular packing and external condition (high temperature) for the decomposition of crystalline TEX are completely different from those for the decomposition of isolated TEX. This may be the main cause for the difference in their decomposition mechanisms.

The generated $\mathrm{H}$ radicals are very active and can prompt other unreacted TEX molecules to decompose. This catalytic role mainly occur through three interesting paths, as shown in Fig. 6: (1) the $\mathrm{H}$ radical attacks the $\mathrm{N}$ atoms in the cage, leading to the $\mathrm{N}-\mathrm{NO}_{2}$ bond homolysis, (2) the $\mathrm{H}$ radical attacks the $\mathrm{C}-\mathrm{C}$ bond, opening the cage structure, and (3) the $\mathrm{H}$ radical attacks the $\mathrm{C}-\mathrm{N}$ bond, opening the cage structure. The catalytic behavior of the hydrogen radical is similar to that described in previous reports, such as studies on the thermal decompositions of PETN $^{23}$ and crystalline furoxan ${ }^{19}$ by $a b$ initio MD simulations.

Fig. 7 presents the snapshots for the release mechanism (slow formation and disintegration of polycyclic networks) of nitrogen gas in the later decomposition stage of crystal TEX molecules. Note that the equilibrium established herein (for all the later species) is dynamic, i.e., previously formed molecules can further react and undergo rearrangements. After the initial decomposition reaction took place, there were many chain reactions occurring in the TEX molecules. At $10.982 \mathrm{ps}$, one NO combined with one $\mathrm{HNO}$ to form one $\mathrm{HON}=\mathrm{NO}$. Then, $\mathrm{HON}=$ NO decomposed to produce $\mathrm{N}=\mathrm{NO}$ and $\mathrm{OH}$ radicals at 10.996

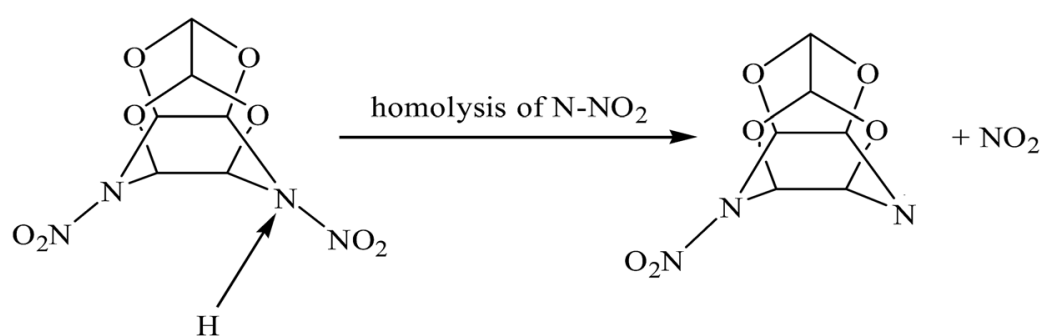

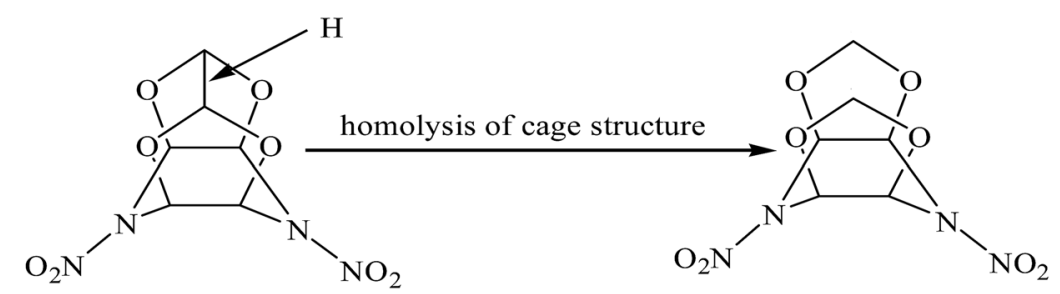

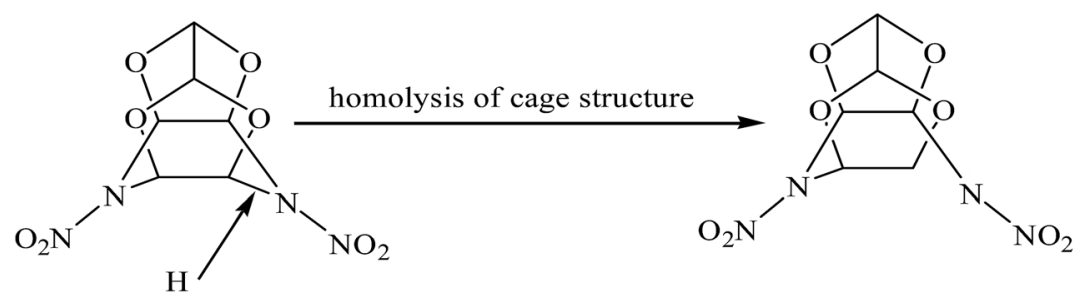

Fig. 6 Three hydrogen-induced initial decomposition paths in the crystal TEX molecule. 

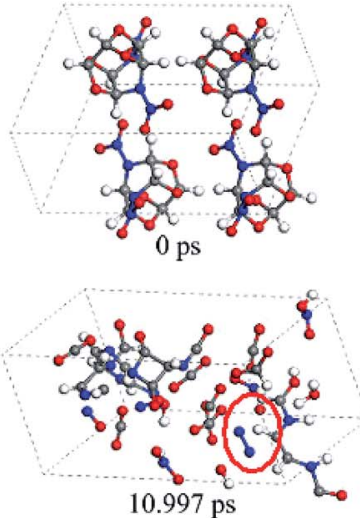
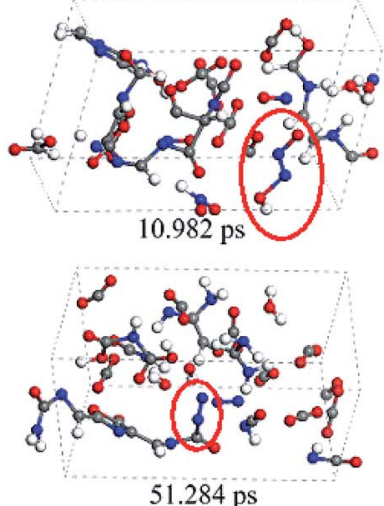
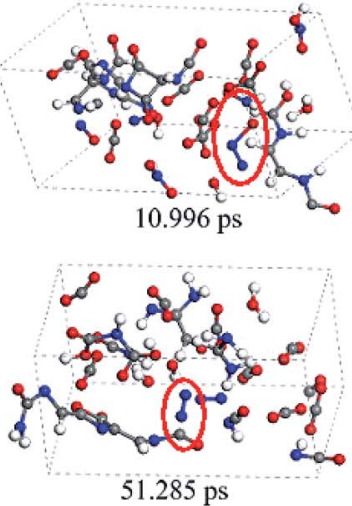

Fig. 7 Snapshots of the mechanism (slow formation and disintegration of polycyclic networks) for the release of nitrogen gas in the later decomposition stage of crystal TEX molecules. Red ovals mark the key formation steps of nitrogen gas.

ps. Next, the $\mathrm{O}-\mathrm{N}$ bond of $\mathrm{N}=\mathrm{NO}$ broke down to rapidly release $\mathrm{N}_{2}$ and an oxygen radical at $10.997 \mathrm{ps}$. After this, TEX molecules continued to decompose to form long chains and complicated carbon-rich heterocyclic rings. As the simulation continued, they split to form small fragments after 50 ps. At $51.243 \mathrm{ps}$, the carbon-rich heterocyclic rings broke down to form $\mathrm{R}-\mathrm{N}-\mathrm{NOH}$. Subsequently, $\mathrm{R}-\mathrm{N}-\mathrm{NOH}$ rearranged to form $\mathrm{N}=\mathrm{NC}-\mathrm{R}$, which further decomposed to produce $\mathrm{N}_{2}$ and a fragment. Despite the different paths leading to $\mathrm{R}_{1}-\mathrm{N}=\mathrm{N}-\mathrm{R}_{2}$, the release mechanism of nitrogen gas was found to be the same during the whole decomposition stage. Our findings are different from the mechanism for the nitrogen release during the thermal decompositions of the high-energy crystal DiAT. ${ }^{9}$ This may be due to their structural differences.

The abovementioned observations were obtained from the simulations on a $2 \times 1 \times 1$ supercell. To validate the reliability of these simulations, we performed one additional simulation on a larger $3 \times 1 \times 1$ supercell. Fig. 8 presents the snapshots for the release mechanism of nitrogen gas during the decomposition of crystal TEX molecules using the $3 \times 1 \times 1$ supercell. Overall, after the decomposition of TEX was triggered, some long chains and complicated carbon-rich heterocyclic rings were formed, and then they split to form small fragments. At $3.204 \mathrm{ps}$, the carbon-rich heterocyclic ring broke to produce $\mathrm{N}=$
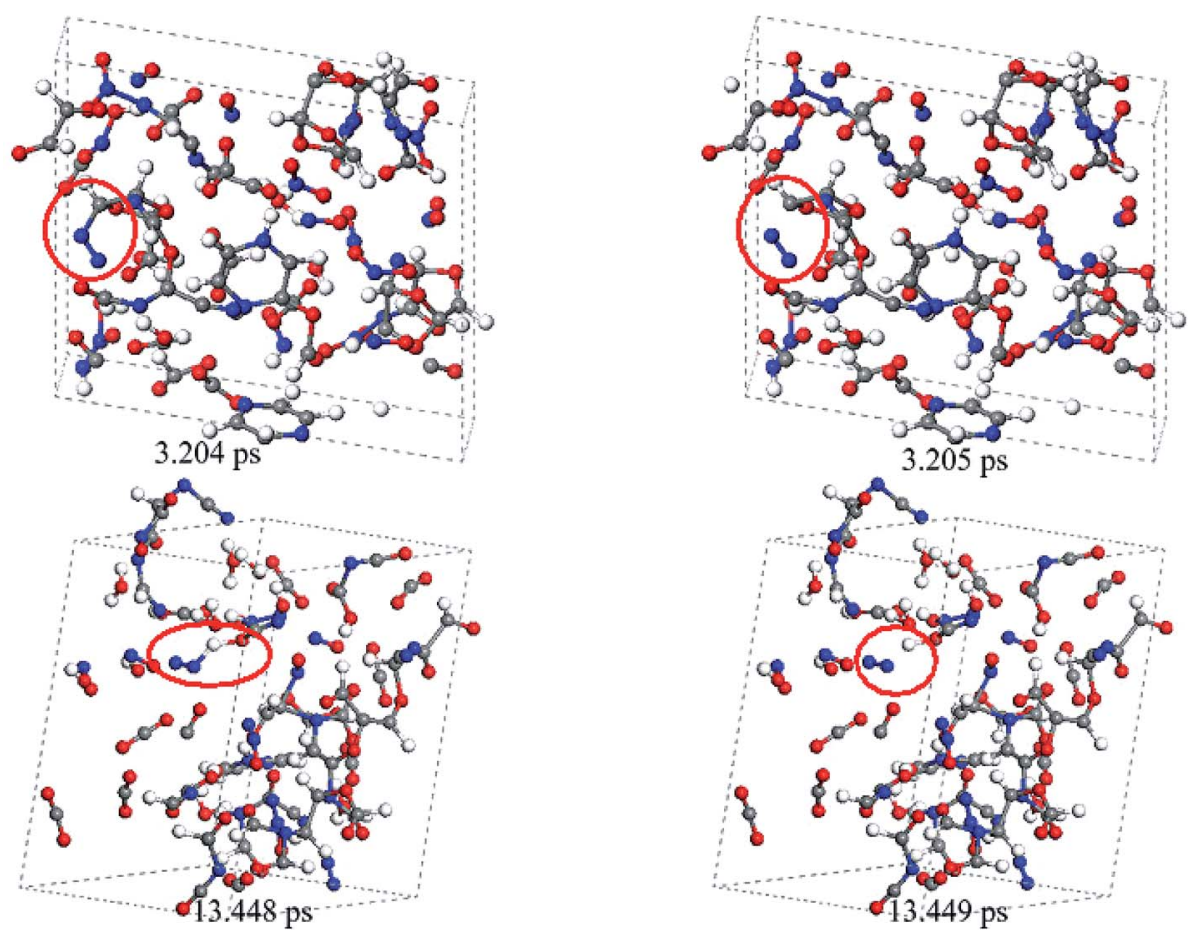

Fig. 8 Snapshots for the release mechanism of nitrogen gas in crystal TEX molecules, obtained from the simulations performed on a $3 \times 1 \times 1$ supercell. 
$\mathrm{NC}-\mathrm{R}$. After this, $\mathrm{N}=\mathrm{NC}-\mathrm{R}$ rapidly decomposed to form $\mathrm{N}_{2}$ and a fragment. In addition, $\mathrm{HON}-\mathrm{NH}$ radicals were observed in the system. At $13.448 \mathrm{ps}, \mathrm{HON}-\mathrm{NH}$ decomposed to release $\mathrm{N}_{2}$. The release mechanism of nitrogen gases observed in the $3 \times 1 \times 1$ supercell is the same as that observed in the $2 \times 1 \times 1$ supercell. Although enlarging the system size can produce more decomposition and combination reactions and lead to the formation of larger and more complicated polycyclic networks, we did not observe significant differences in the release mechanism of nitrogen gas between the simulations on the two supercells. Therefore, a $2 \times 1 \times 1$ supercell is sufficient to observe the most important features of the decomposition process.

The release of carbon dioxide as a main product is very fast during the whole decomposition stage of crystal TEX molecules. It is seen in Fig. 9 that $\mathrm{R}_{1}-\mathrm{CO}_{2}-\mathrm{R}_{2}$ could be formed by two different mechanisms: one is through ${ }_{0}^{\mathrm{O}=\mathrm{C}-\mathrm{R}}$ fragments, and the other one is through $\mathrm{O}=\mathrm{C}=\mathrm{O}-\mathrm{R}$ fragments. Then, $\mathrm{R}_{1}-\mathrm{CO}_{2}-\mathrm{R}_{2}$ breaks to produce $\mathrm{CO}_{2}$ and other small radicals. At $3.237 \mathrm{ps}$, the cage of one TEX molecule rapidly breaks to form a $\prod_{\mathrm{O}}^{\mathrm{O}=\mathrm{C}-\mathrm{C}-\mathrm{R}}$ fragment and $\mathrm{CO}_{2}$. In the ${ }_{\mathrm{O}}^{\mathrm{O}=\mathrm{C}-\mathrm{C}-\mathrm{R}}$ fragment, the $\mathrm{C}-\mathrm{C}$ bond opened to release another $\mathrm{CO}_{2}$ molecule at 14.524 ps. The subsequent four $\mathrm{CO}_{2}$ molecules were rapidly released by the same decomposition mechanism, with the ${ }_{\mathrm{O}}^{\mathrm{O}=\mathrm{C}-\mathrm{C}-\mathrm{R}}$ fragments cleaving the $\mathrm{C}-\mathrm{H}$ bonds at 4.082, 4.605, 6.128, and $20.216 \mathrm{ps,}$ respectively. At $9.423 \mathrm{ps}$, one $\mathrm{CO}_{2}$ was released by the cleavage of the $\mathrm{O}-\mathrm{H}$ bond in the $\mathrm{O}=\mathrm{C}=\mathrm{O}-\mathrm{H}-\mathrm{R}$ fragment. Finally, the other three $\mathrm{CO}_{2}$ were produced by the cleavage of the $\mathrm{C}-\mathrm{N}$ bond in the $\underset{\mathrm{H}-\mathrm{R}}{\mathrm{O}=\mathrm{C}=\mathrm{O}}$ fragments at $10.335,14.518$, and $15.556 \mathrm{ps}$, respectively. Only two mechanisms for the release of carbon dioxide gas were found during the whole decomposition process. One decomposition mechanism occurs via the $\mathrm{C}-\mathrm{R}$ bond cleavage and the other via the $\mathrm{O}-\mathrm{R}$ bond cleavage.

It was observed that there are many multimolecular reactions during the decomposition of TEX. Fig. 10 displays the snapshots of the ring cleavage and the unstable long chain and heterocyclic formation throughout the decomposition process of the crystal TEX molecules. At $2.210 \mathrm{ps,} \mathrm{one} \mathrm{TEX} \mathrm{molecule}$ decomposed to form a six-membered heterocycle and other small molecules. Then, three TEX molecules reacted to form three unstable small chains at 2.67 ps. Two small chains linked
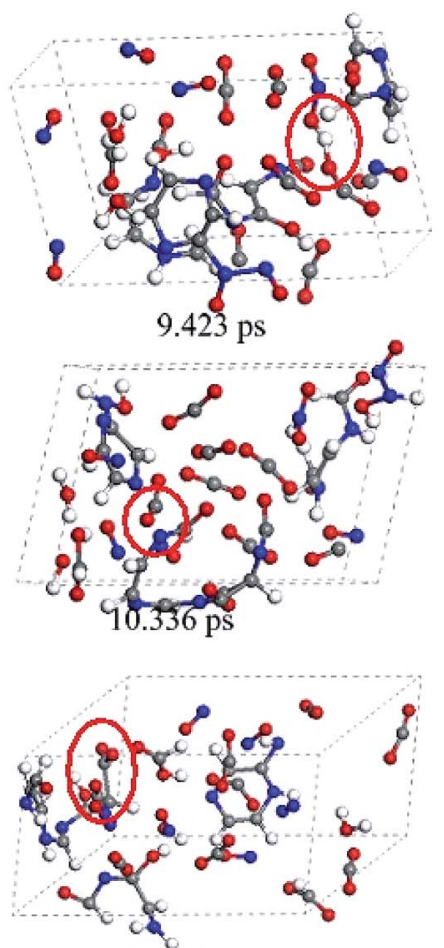

$14.524 \mathrm{ps}$

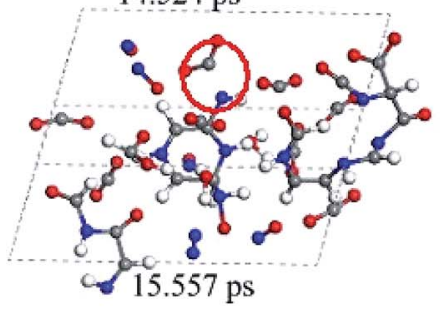

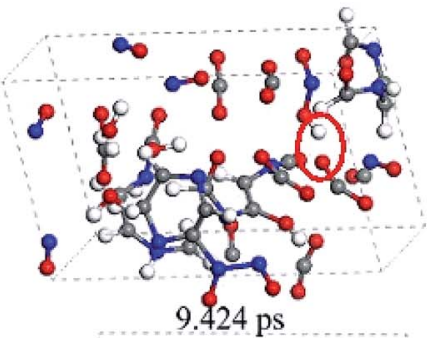
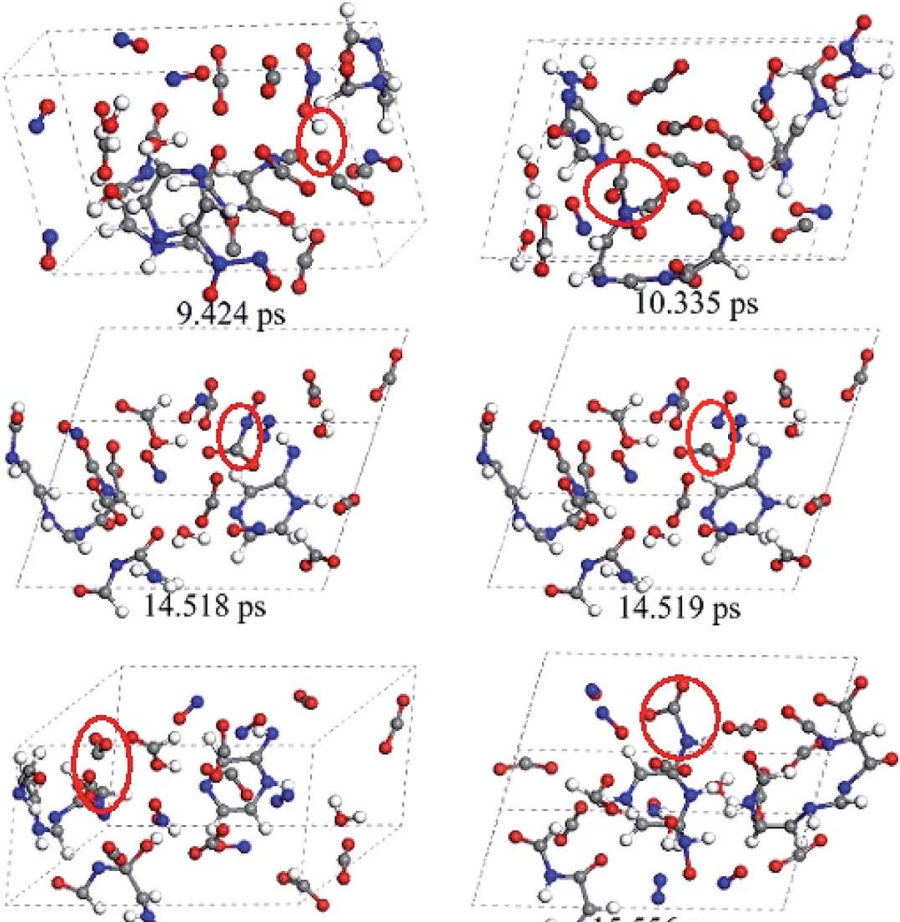

$14.525 \mathrm{ps}$
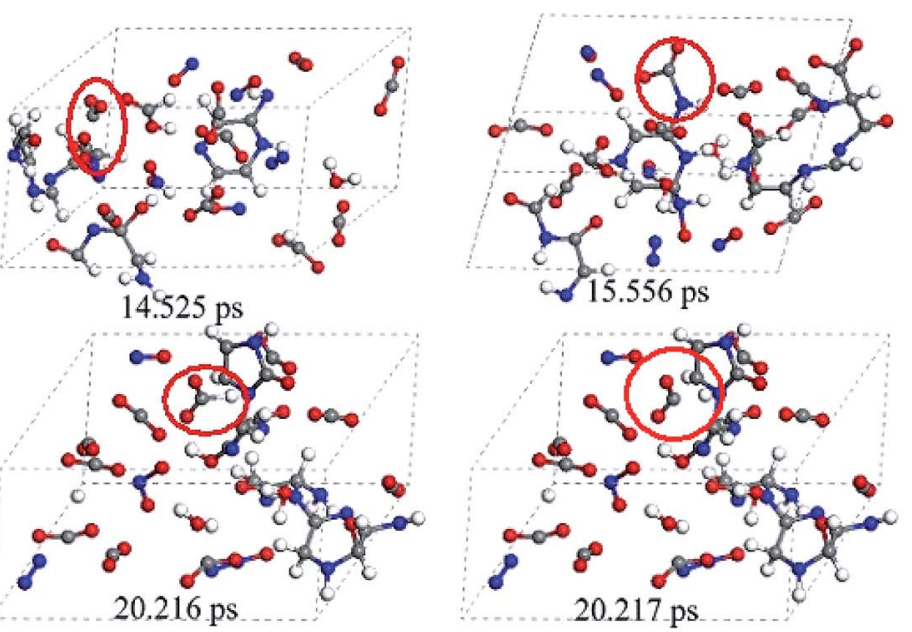

Fig. 9 Snapshots for the release mechanism of carbon dioxide throughout the decomposition process of the crystal TEX molecules. Red ovals mark the key steps for the formation of $\mathrm{CO}_{2}$. 

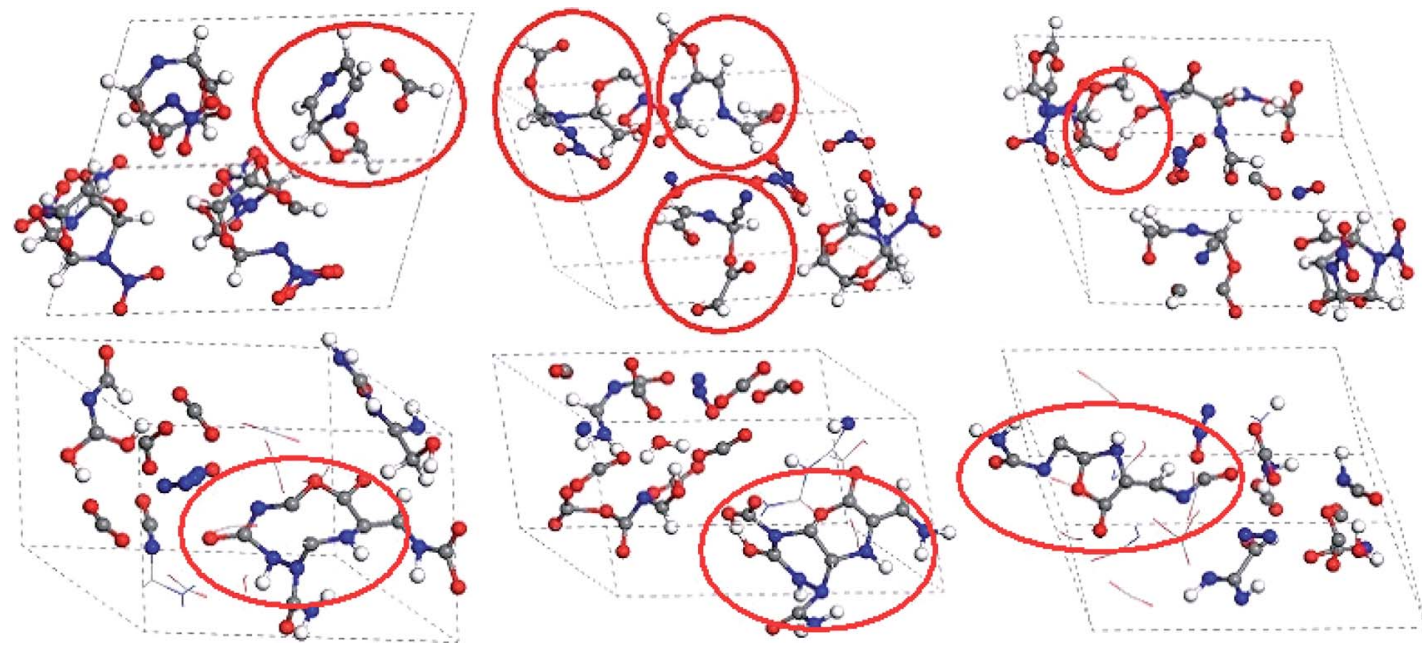

Fig. 10 Snapshots for the formation of rings, unstable long chains, and heterocyclic clusters throughout the decomposition process of the crystal TEX molecules. Red ovals mark the key steps.
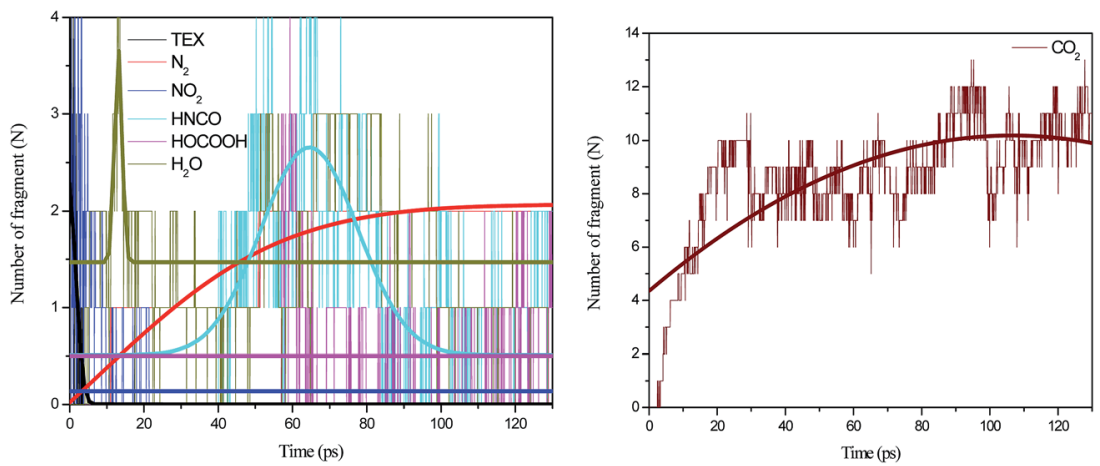

Fig. 11 Time evolution for the molecules produced throughout the decomposition process of crystal TEX molecules: $\mathrm{N}_{2}, \mathrm{NO}_{2}, \mathrm{NO}_{1} \mathrm{HNCO}_{\text {, }}$ $\mathrm{HOCOOH}, \mathrm{H}_{2} \mathrm{O}$, and $\mathrm{CO}_{2}$. The thick trend lines correspond to the actual concentration data of the corresponding matching color.

to form a longer chain at $2.938 \mathrm{ps}$. At $34.402 \mathrm{ps}$, the whole molecular cage had decomposed to form an unstable tenmembered heterocycle. Then, at $35.730 \mathrm{ps}$, this heterocycle further decomposed to form a tricycle that also decomposed to finally produce various gases and small fragments at $50 \mathrm{ps}$.

Fig. 11 presents the time evolution of the population of the main fragments during the decomposition of the crystal TEX molecules. The decomposition of TEX completed in 20 ps. Therefore, the 130 ps simulation time is almost sufficient to reach the equilibrium concentrations of the decomposition products. Since the unimolecular $\mathrm{N}-\mathrm{NO}_{2}$ cleavage is the main step in the decomposition of the TEX crystal, the release of nitro groups is very fast. This is supported by our observations that the completion of the $\mathrm{N}-\mathrm{NO}_{2}$ cleavage only requires $1 \mathrm{ps}$. Most of the $\mathrm{NO}_{2}$ molecules were formed at about $20 \mathrm{ps}$. After this, the formation of $\mathrm{NO}_{2}$ requires about 50 ps. Further, during the decomposition, neither NO nor $\mathrm{N}_{2}$ reached the equilibrium concentrations, and moreover, the lifetimes for $\mathrm{NO}_{2}$ and $\mathrm{NO}$ were significantly prolonged. The decrease in the concentration of NO was hardly noticeable but still faster than that of $\mathrm{N}_{2}$. The formation of molecular nitrogen was expected to be delayed for
0.5 ps. $\mathrm{CO}_{2}$ was mostly produced during the latter decomposition stage, reaching a concentration of nine to twelve molecules. The concentration of $\mathrm{HOCOOH}$ was from one to four molecules per unit cell by the end of the simulation. HNCO was formed after 10 ps. The concentration of HNCO reached its peak at about $75 \mathrm{ps}$, and then smoothly decreased. Water was produced at $4.1 \mathrm{ps}$, amounting to about four $\mathrm{H}_{2} \mathrm{O}$ molecules per unit cell. The concentration of $\mathrm{H}_{2} \mathrm{O}$ reached its peak at about $65 \mathrm{ps}$, and then smoothly decreased. $\mathrm{HOCOOH}, \mathrm{HNCO}$, and $\mathrm{H}_{2} \mathrm{O}$ disappeared due to their reactive lone pair electrons. The primary decomposition products of the TEX crystal are nitrogen and various carboxyl derivatives.

\section{Conclusions}

In this study, AIMD simulations were performed to study the chemical events in the decomposition of isolated and crystal TEX molecules at high temperatures. It was found that there are three different initial reactions involved in the decomposition of the isolated TEX molecule: (a) the $\mathrm{N}-\mathrm{NO}_{2}$ bond cleavage to release $\mathrm{NO}_{2}$; (b) the $\mathrm{N}-\mathrm{NO}_{2}$ bond cleavage and ring opening in 
the concerted step; and (c) the ring opening through the $\mathrm{C}-\mathrm{C}$ bond cleavage. The activation energy barriers for the initial decomposition reactions indicate that at high temperatures, among the three initial reactions, the nitrogen-nitro cleavage is the easiest path to trigger the decomposition of the TEX molecule.

The decomposition of the crystal TEX molecules is triggered by the breaking of the unimolecular $\mathrm{C}-\mathrm{H}$ bond to form a hydrogen radical. The generated $\mathrm{H}$ radicals can promote the decomposition of other unreacted TEX molecules. Moreover, there are many multimolecular TEX reactions during the decomposition. Overall, after the decomposition of the crystal TEX molecules was triggered, some long chains and complicated carbon-rich heterocyclic rings were formed, and then they split to form small fragments: $\mathrm{N}_{2}, \mathrm{NO}_{2}$, NO, HNCO, $\mathrm{HOCOOH}$, $\mathrm{H}_{2} \mathrm{O}$, and $\mathrm{CO}_{2}$.

This study may provide useful information for understanding the decomposition mechanisms of cage explosives and for developing new high-energy explosives.

\section{Acknowledgements}

This work was supported by the NSAF Foundation of the National Natural Science Foundation of China and the China Academy of Engineering Physics (Grant No. U1530104), the National Natural Science Foundation of China (Grant No. 21273115), and a Project Funded by the Priority Academic Program Development of the Jiangsu Higher Education Institutions.

\section{References}

1 Y. Bayat and V. Azizkhani, J. Energ. Mater., 2012, 30, 209-219. 2 E. C. Koch, Propellants, Explos., Pyrotech., 2015, 40, 374-387. 3 J. A. Vagenknecht, P. Marecek and W. A. Trzcinski, J. Energ. Mater., 2002, 20, 245-253.

4 M. B. Talwar, J. K. Nair, R. S. Palaiah, T. Mukundan and S. P. Gejji, Def. Sci. J., 2002, 52, 157-163.
5 D. M. Badgujar, M. B. Talawar, S. N. Asthana and P. P. Mahulikar, J. Hazard. Mater., 2008, 151, 289-305.

6 A. E. Mattsson, P. A. Schultz, M. P. Desjarlais, T. R. Mattsson and K. Leung, Modell. Simul. Mater. Sci. Eng., 2005, 13, R1R13.

7 R. Iftimie, P. Minary and M. E. Tuckerman, Proc. Natl. Acad. Sci., 2005, 102, 6654-6659.

8 O. Isayev, L. Gorb, M. Qasim and J. Leszczynski, J. Phys. Chem. B, 2008, 112, 11005-11013.

9 Q. Wu, W. H. Zhu and H. M. Xiao, Phys. Chem. Chem. Phys., 2014, 16, 21620-21628.

10 C. C. Ye, Q. An, W. A. Goddard III, T. heng, S. Zybin and X. H. Ju, J. Phys. Chem. C, 2015, 119, 2290-2296.

11 Q. Wu, H. Chen, G. L. Xiong, W. H. Zhu and H. M. Xiao, J. Phys. Chem. C, 2015, 119, 16500-16506.

12 Q. Wu, G. L. Xiong, W. H. Zhu and H. M. Xiao, Phys. Chem. Chem. Phys., 2015, 17, 22823-22831.

13 W. Kohn and L. J. Sham, Phys. Rev., 1965, 140, 1133-1138.

14 P. Hohenberg and W. Kohn, Phys. Rev. [Sect.] B, 1964, 136, B864-B871.

15 M. D. Segall, P. J. D. Lindan, M. J. Probert, C. J. Pickard, P. J. Hasnip, S. J. Clark and M. C. Payne, J. Phys.: Condens. Matter, 2002, 14, 2717-2744.

16 N. Troullier and J. Martins, Phys. Rev. B: Condens. Matter Mater. Phys., 1991, 43, 1993-2006.

17 J. P. Perdew, K. Burke and M. Ernzerhof, Phys. Rev. Lett., 1996, 77, 3865-3868.

18 S. Nose, J. Chem. Phys., 1984, 81, 511-519.

19 Q. Wu, W. H. Zhu and H. M. Xiao, RSC Adv., 2014, 4, 3445434459.

20 M. H. V. Huynh, M. A. Hiskey, J. G. Archuleta, E. L. Roemer and R. Gilardi, Angew. Chem., Int. Ed., 2004, 43, 5658-5661.

21 L. Turker, Def. Technol., 2014, 10, 328-333.

22 D. Chakraborty, R. P. Muller, S. Dasgupta and W. A. Goddard, J. Phys. Chem. A, 2001, 105, 1302-1314.

23 C. J. Wu, L. E. Freid, L. H. Yang, N. Goldman and S. Bastea, Nat. Chem., 2009, 1, 57-62. 